\title{
Catalytic Ozonation of Herbicide 2,4-D over Cobalt Oxide Supported on Mesoporous Zirconia
}

\author{
Chun Hu,* Shengtao Xing, Jiuhui Qu, and Hong He \\ State Key Laboratory of Environmental Aquatic Chemistry, Research Center for Eco-Environmental Sciences, \\ Chinese Academy of Sciences, Beijing 100085, China
}

Received: December 5, 2007; In Final Form: February 2, 2008

\begin{abstract}
Cobalt oxide was supported on ordered mesoporous zirconia (MZ) by wet impregnation, drying, water washing, and calcinations with cobalt acetate tetrahydrate as the metal precursor for the first time. The material $\left(\mathrm{CoO}_{x} /\right.$ MZIW) was characterized by X-ray diffraction, X-ray photoelectron spectroscopy, Fourier transform infrared spectroscopy, temperature-programmed reduction, and UV-vis diffuse reflectance spectra measurement. The studies showed that the $\left[\mathrm{Co}\left(\mathrm{H}_{2} \mathrm{O}\right)_{6}\right]^{2+}$ interacted strongly with surface hydroxyls of mesoporous zirconia, leading to a highly dispersed $\mathrm{CoO}_{x}$ layer. The $\mathrm{CoO}_{x}$ existed mainly as $\mathrm{Co}_{3} \mathrm{O}_{4}$ phase. Furthermore, the catalyst was found to be highly effective for the mineralization of 2,4-dichlorophenoxyacetic acid (2,4-D) aqueous solution with ozone. The multivalence oxidation states and high dispersion of $\mathrm{CoO}_{x}$ enhanced the interfacial electron transfer, causing the higher catalytic reactivity. On the basis of all information obtained under different experimental conditions, $\mathrm{CoO}_{x}$ /MZIW enhanced the mineralization of 2,4-D by the formation of the hydroxyl radical $\left({ }^{\circ} \mathrm{OH}\right)$ resulting from the catalytic decomposition of ozone.
\end{abstract}

\section{Introduction}

Heterogeneous catalytic ozonation has received increasing attention in recent years because of its potentially higher effectiveness in the degradation and mineralization of refractory organic pollutants and lower negative effect on water quality. It has been developed to overcome the limitations of ozonation processes, such as the formation of byproducts and selective reactions of ozone, which are designed to enhance the production of ${ }^{\bullet} \mathrm{OH}$, known nonselective oxidants. ${ }^{1,2}$ Specifically, solid metal oxides are more practical in catalytic ozonation than ionized metals, due to the fact that solid metal oxides subdue bromate formation in the reaction with ozone and are less $\mathrm{pH}$-sensitive than ionized metals. ${ }^{3,4}$

So far, metal oxides (e.g., $\mathrm{MnO}_{2}, \mathrm{TiO}_{2}$, and $\mathrm{Al}_{2} \mathrm{O}_{3}$ ) and supported metal oxides have been proposed as effective catalysts for ozonation processes. ${ }^{5-7}$ In many cases, alumina-supported metal oxides of $\mathrm{Fe}, \mathrm{Ag}, \mathrm{Co}, \mathrm{Ni}, \mathrm{Mn}$, and $\mathrm{Cu}$ have shown high activity for ozone decomposition at ambient temperature. ${ }^{8}$ Among transition metal oxides, cobalt oxides, both unsupported and supported on different oxide support materials, are some of the most important catalysts for complete oxidation of volatile organic compounds in air. ${ }^{9}$ A large number of papers have reported their high catalytic activity for the elimination of $\mathrm{CO},{ }^{10}$ $\mathrm{NO}_{x},{ }^{11}$ and organic compounds ${ }^{12}$ in air. However, these catalysts have not yet been applied much for the catalytic ozonation of organic pollutants in water. ${ }^{13}$

The catalytic activity of metal oxide depends on the size distribution and morphology of particles. Hence, reducing the diameter of heterogeneous catalysts to nanometer scale may cause the enhanced reactivity of the heterogeneous catalysts at a given amount. ${ }^{14}$ Presently, using porous materials as solid nanoreactors, $\mathrm{MnO}_{x}$ nanocrystals with various morphologies have been obtained by a method called "nanocasting". Generally,

* Corresponding author. Tel: +86-10-62849628; fax: +86-10-62923541; e-mail: huchun@rcees.ac.cn. inorganic precursors are first introduced into channels of host materials such as mesoporous silicas. Then, $\mathrm{MnO}_{x}$ nanocrystals are produced with a replica of the confined space by subsequent calcinations. Nanoparticles of $\mathrm{MnO}_{x}$ supported on mesoporous silica SBA-15 have been obtained by high dispersion. ${ }^{15}$ The structure and dispersion of the supported metal oxide depend primarily on the preparation method, the nature of the support, and the type of precursor itself. Ordered mesoporous materials, with their intrinsically high surface areas, are particularly suitable for this purpose.

In the present study, for the first time, $\mathrm{CoO}_{x}$ nanoparticles were highly dispersed on the surface of $\mathrm{MZ}$ by the impregnation of the acetate precursor solution, followed by drying at $383 \mathrm{~K}$ and washing with water and calcinations at $573-773 \mathrm{~K}$. This was attributed to the strong interaction of the $\left[\mathrm{Co}\left(\mathrm{H}_{2} \mathrm{O}\right)_{6}\right]^{2+}$ with surface hydroxyls of $\mathrm{MZ}$ on the basis of different experimental information. 2,4-D is the most widely used herbicide in the world. ${ }^{16}$ It has been detected as a major pollutant in ground and surface waters. Moreover, 2,4-D has very poor biodegradability. Most papers describe the degradation of 2,4-D aqueous solution by advanced oxidation processes (AOPs) involving chemical, ${ }^{17}$ photochemical, ${ }^{18}$ or photocatalytic ${ }^{19}$ production of - $\mathrm{OH}$. In these processes, the mineralization of 2,4-D needs a prolonged reaction time. Catalytic ozonation has great potential for the mineralization of refractory organics. Therefore, 2,4-D was selected to evaluate the activity and properties of the catalyst with ozone in aqueous solution. The results indicated that the catalyst exhibited higher reactivity for the mineralization of 2,4D. A preliminary effort to identify a correlation between the surface properties of supported $\mathrm{CoO}_{x}$ and their catalytic activity has been undertaken.

\section{Experimental Section}

Catalyst Preparation. MZ was prepared via solid-state reaction using the structure-directing method. ${ }^{20}$ In this synthesis, $\mathrm{ZrOCl}_{2} \cdot 8 \mathrm{H}_{2} \mathrm{O}$ and $\mathrm{NaOH}$ were milled into fine powder, 
respectively, and mixed at ambient temperature with the assistance of P123. The mixture was then transferred into an autoclave and kept at $383 \mathrm{~K}$ for $48 \mathrm{~h}$. Subsequently, the mixture was washed with deionized water and ethanol, then dried at $383 \mathrm{~K}$ overnight and calcined at $623 \mathrm{~K}$ for $3 \mathrm{~h}$. Because MZ has ordered mesoporous and a bigger BET surface area (232 $\mathrm{m}^{2} / \mathrm{g}$ ) with sufficient hydroxyl groups, it is a good support for preparing the highly dispersed metal oxide. Different supported $\mathrm{CoO}_{x}$ samples were prepared by the incipient wetness impregnation method with cobalt acetate tetrahydrate $\left[\mathrm{Co}\left(\mathrm{CH}_{3} \mathrm{COO}\right)_{2}\right.$. $\left.4 \mathrm{H}_{2} \mathrm{O}\right]$ as the metal precursor. A 0.33 -g quantity of cobalt acetate tetrahydrate was dissolved in $1 \mathrm{~mL}$ of distilled water. Then, $2 \mathrm{~g}$ of $\mathrm{MZ}$ was added to this solution. After impregnation, the sample was dried at $110{ }^{\circ} \mathrm{C}$ for several hours. Subsequently, the product was washed with deionized water to remove the excess cobalt, which was not connected directly to the surface of $\mathrm{MZ}$ by the hydroxyl group, and dried at $110^{\circ} \mathrm{C}$ for several hours and calcined at $350{ }^{\circ} \mathrm{C}$ for $2 \mathrm{~h}$, in air. Following this procedure, catalysts with different Co contents were prepared from 1 to $20 \mathrm{wt} \%$. The catalyst with $2 \mathrm{wt} \%$ Co exhibited the highest activity. This catalyst, designated $\mathrm{CoO}_{x} / \mathrm{MZIW}$, was used for all of the experiments. As reference, two catalysts, 2 wt \% $\mathrm{Co}$ supported on mesoporous zirconia and commercial $\mathrm{ZrO}_{2}$ (CZ) (purchased from Shantou Xilong Chemical Factory Guangdong, China), were prepared by the above method without water washing. These two catalysts were designated $\mathrm{CoO}_{x} / \mathrm{MZI}$ and $\mathrm{CoO}_{x} / \mathrm{CZI}$.

Catalyst Characterization. Powder X-ray diffraction of the catalyst was recorded on a Scintag-XDS-2000 diffractometer with $\mathrm{Cu} \mathrm{K} \alpha$ radiation $(\lambda=1.54059 \AA)$. UV-vis diffuse reflectance spectra (UV-vis DRS) of the samples were recorded on a UV-vis spectrophotometer (Hitachi UV-3100) with an integrating sphere attachment. The analyzed range was 200$800 \mathrm{~nm}$, and $\mathrm{BaSO}_{4}$ was the reflectance standard. XPS analysis was performed on an AXIS-Ultra instrument from Kratos, using monochromatic $\mathrm{Al} \mathrm{K} \alpha$ radiation $(225 \mathrm{~W}, 15 \mathrm{~mA}, 15 \mathrm{kV})$. To compensate for surface charge effects, binding energies were calibrated using a C1s hydrocarbon peak at $284.8 \mathrm{eV}$. For FTIR measurement, the dry samples were supported on $\mathrm{KBr}$ pellets. The infrared spectrum was recorded on a Nicolet FTIR spectrophotometer. The zeta potential of catalysts in $\mathrm{KNO}_{3}\left(10^{-3}\right.$ M) solution were measured with a Zetasizer 2000 (Malvern Co., U.K.). Every reading of the instrument was recorded after three consistent readings had been attained. The temperatureprogrammed reduction (TPR) experiments were carried out in a flow of $5 \% \mathrm{H}_{2} / \mathrm{Ar}(30 \mathrm{~mL} / \mathrm{min})$ by heating the sample to $900{ }^{\circ} \mathrm{C}$ at $10{ }^{\circ} \mathrm{C} \mathrm{min}^{-1}$. A mass spectrometer (Hiden) was used for on-line monitoring of the TPR effluent gas. Prior to TPR, the catalyst $(0.5 \mathrm{~g})$ was pretreated under a $20 \% \mathrm{O}_{2} / \mathrm{He}$ mixture at $350{ }^{\circ} \mathrm{C}$ for $1 \mathrm{~h}$ and cooled to room temperature.

Catalytic Activity Measurements. Batch experiments were carried out with a 1.2-L reactor. The reaction temperature was maintained at $20{ }^{\circ} \mathrm{C}$. In a typical experiment, aqueous suspensions of 2,4-D ( $\left.1 \mathrm{~L}, 80 \mathrm{mg} \mathrm{L}^{-1}\right)$ and $1.5 \mathrm{~g}$ of catalyst powders were placed in the reactor. The suspension was magnetically stirred throughout this experiment. The ozone was generated by a laboratory ozonizer (DHX-SS-IG, Harbin Jiujiu Electrochemistry Technology Co., Ltd., China). Thirty milligrams of gaseous $\mathrm{O}_{3} / \mathrm{L}$ oxygen-ozone was bubbled into the reactor through the porous plate of the reactor bottom at a $12 \mathrm{~L} \mathrm{~h}^{-1}$ flow rate. At given time intervals, samples were withdrawn and filtered through a Millipore filter (pore size $0.45 \mu \mathrm{m}$ ) for analysis. An aliquot of $0.1 \mathrm{M} \mathrm{Na}_{2} \mathrm{~S}_{2} \mathrm{O}_{3}$ was subsequently added to the sample to quench the aqueous ozone remaining in the

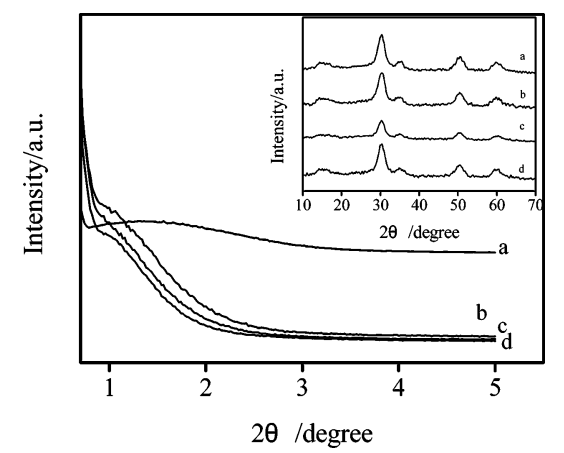

Figure 1. XRD patterns of different catalysts: (a) $\mathrm{MZ}$, (b) $1 \% \mathrm{CoO}_{x} /$ MZIW, (c) $2 \% \mathrm{CoO}_{x} / \mathrm{MZIW}$, (d) $\mathrm{CoO}_{x} / \mathrm{MZI}$. The inset shows the highangle peak.

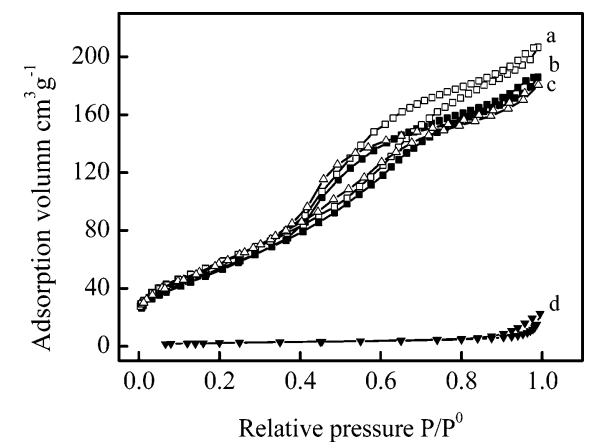

Figure 2. $\mathrm{N}_{2}$ adsorption-desorption isotherms: (a) $\mathrm{CoO}_{x} / \mathrm{MZIW}$, (b) $\mathrm{CoO}_{x} / \mathrm{MZI}$, (c) MZ, (d) $\mathrm{CoO}_{x} / \mathrm{CZI}$.

reaction solution. The concentration of ozone in the aqueous phase was determined with the indigo method. 2,4-D was measured by high-performance liquid chromatography (HPLC, Alliance 2695) with an Xterra C18 column. Sixty percent acetonitrite with water mobile phase was used. The total organic carbon (TOC) of the solution was analyzed with a Phoenix 8000 TOC analyzer.

\section{Results and Discussion}

XRD and $\mathbf{N}_{2}$ Adsorption. The XRD patterns of different samples are shown in Figure 1. The low-angle XRD pattern of the MZ sample showed a broader primary diffraction peak, indicating that the prepared MZ had an ordered mesostructure. ${ }^{21}$ The inorganic framework was periodic because it consisted of nanocrystallites in the tetragonal phase according to the XRD peaks at high angles shown in the inset of Figure 1. After the introduction of $\mathrm{Co}$, the low-angle XRD peaks of $\mathrm{MZ}$ shifted toward higher angles, although MZ still had a periodic mesoporous framework. This was possibly attributed to the formation of Co nanoparticles in the pores. No XRD diffraction peaks of $\mathrm{CoO}_{x}$ were observed in these samples. However, the peak intensity of $\mathrm{MZ}$ was lowered with the increase of the loading amount of $\mathrm{CoO}_{x}$ for $\mathrm{CoO}_{x} / \mathrm{MZIW}$ (curves b and c), while it was not changed by the addition of $\mathrm{CoO}_{x}$ for $\mathrm{CoO}_{x} / \mathrm{MZI}$. The results indicated that the Co ions were incorporated into the structure of $\mathrm{MZ}$ for $\mathrm{CoO}_{x} / \mathrm{MZIW}$, whereas the Co ions were not incorporated into the crystal phase of $\mathrm{MZ}$ for $\mathrm{CoO}_{x} / \mathrm{MZI}$. The XRD patterns of $\mathrm{CoO}_{x} / \mathrm{CZI}$ and $\mathrm{CZ}$ were same (Supporting Information, Figure S1). No XRD diffraction peaks of $\mathrm{CoO}_{x}$ were observed in $\mathrm{CoO}_{x} / \mathrm{CZI}$ because of its low content.

The $\mathrm{N}_{2}$ adsorption-desorption isotherms are presented in Figure 2 for $\mathrm{MZ}, \mathrm{CoO}_{x} / \mathrm{MZIW}$ and $\mathrm{CoO}_{x} / \mathrm{MZI}$. They are typically type-IV with hysteresis loops, which means that the materials had a mesoporous structure. The introduction of $\mathrm{CoO}_{x}$ 


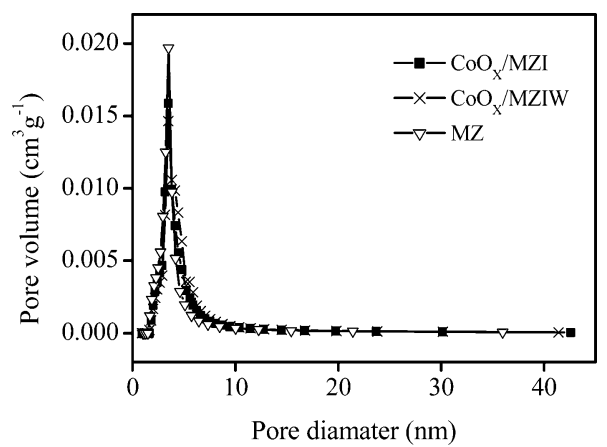

Figure 3. Pore size distribution for $\mathrm{CoO}_{x} / \mathrm{MZIW}, \mathrm{CoO}_{x} / \mathrm{MZI}$, and MZ

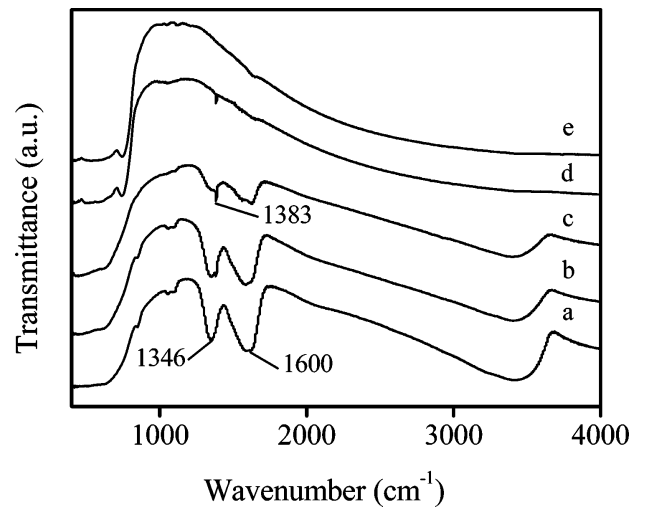

Figure 4. FTIR spectra of different samples: (a) MZ, (b) $\mathrm{CoO}_{x} / \mathrm{MZI}$, (c) $\mathrm{CoO}_{x} / \mathrm{MZIW},(\mathrm{d}) \mathrm{CoO}_{x} / \mathrm{CZI}$, (e) CZ.

did not change the distribution of the pore diameters (shown in Figure 3), indicating the high dispersion of $\mathrm{CoO}_{x}$. However, the BET surface area of $\mathrm{CoO}_{x} / \mathrm{MZIW}$ was $206 \mathrm{~m}^{2} / \mathrm{g}$, smaller than that of MZ, while the BET surface area of $\mathrm{CoO}_{x} / \mathrm{MZI}$ was $193 \mathrm{~m}^{2} / \mathrm{g}$, a significant reduction. As a reference, CZ was also characterized by $\mathrm{N}_{2}$ adsorption-desorption. Its BET surface area was $8.83 \mathrm{~m}^{2} / \mathrm{g}$. No mesopores were detected in the sample (curve d) in Figure 2.

FTIR Measurements. The surface properties of a catalyst are very important for the degradation of organic pollutants in heterogeneous catalytic ozonation. ${ }^{22}$ Therefore, different catalysts were further characterized with FTIR. As shown in Figure 4 for MZ (Figure 4a), there were three $\mathrm{OH}$ absorption bands: the first one was at $3500-3200 \mathrm{~cm}^{-1}$ corresponding to the stretching of $\mathrm{OH}$ groups of adsorbed water. The second one at $1600 \mathrm{~cm}^{-1}$ was assigned to the bending vibration of adsorbed water. ${ }^{23}$ The third one was at $1346 \mathrm{~cm}^{-1}$, attributed to the deformation vibration of $\mathrm{Zr}-\mathrm{OH} .{ }^{24} \mathrm{CoO}_{x} / \mathrm{MZI}$ and $\mathrm{CoO}_{x} / \mathrm{MZIW}$ exhibited similar FTIR spectra of MZ except for a new absorption peak at $1386 \mathrm{~cm}^{-1}$, assigned to $\mathrm{OH}$ deformation vibrations of hydrated $\mathrm{CoO}_{x}$ (Figure $4 \mathrm{~b}$ and $\mathrm{c}$ ). However, for $\mathrm{CoO}_{x} / \mathrm{MZIW}$, the intensity of the new peak was much stronger, and these bands at 1346 and $1600 \mathrm{~cm}^{-1}$ became weaker than that for MZ. Oppositely, these bands did not significantly change in the $\mathrm{CoO}_{x} / \mathrm{MZI}$ sample. The results indicated that $\mathrm{CoO}_{x}$ strongly interacted with surface hydroxyls of $\mathrm{MZ}$ in $\mathrm{CoO}_{x} /$ MZIW, which agreed with the XRD results. The water washing process enhanced the diffusing of $\mathrm{Co}$ (II) on the surface of $\mathrm{MZ}$, leading the strong interaction. There were no $\mathrm{OH}$ groups on $\mathrm{CZ}$ (Figure 4e), except the bands corresponding to a weak $\mathrm{OH}$ stretching vibration $\left(3400 \mathrm{~cm}^{-1}\right) . \mathrm{CoO}_{x} / \mathrm{CZI}$ also exhibited a weak peak at $1386 \mathrm{~cm}^{-1}$, assigned to $\mathrm{OH}$ deformation vibrations of hydrated $\mathrm{CoO}_{x}$.

XPS and UV-Vis DRS Analysis. The dispersion of $\mathrm{CoO}_{x}$ on different samples was further studied by the distribution of

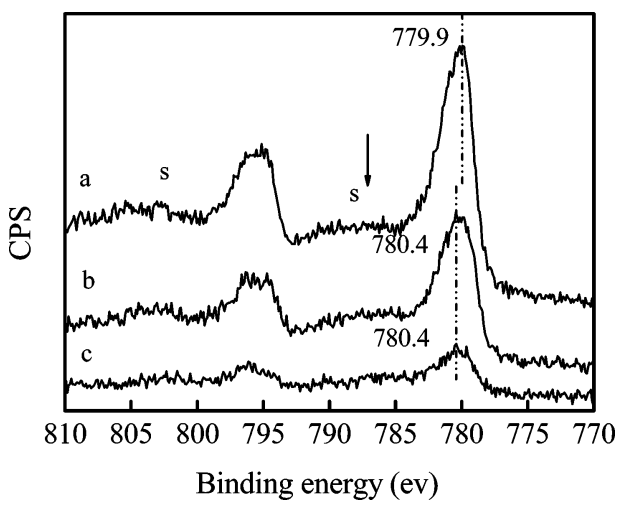

Figure 5. XPS Co $2 p$ spectra of different supported $\mathrm{CoO}_{x}$ : (a) $\mathrm{CoO}_{x} /$ CZI, (b) $\mathrm{CoO}_{x} / \mathrm{MZIW}$, (c) $\mathrm{CoO}_{x} / \mathrm{MZI}$.

TABLE 1: Co Concentration in the Whole Particle and the Surface Phase of Different Catalysts

\begin{tabular}{lcc}
\hline \multicolumn{1}{c}{ sample } & Co in the bulk (wt \%) & Co on the surface $($ wt $\%)$ \\
\hline $\mathrm{CoO}_{x} /$ MZIW & 1.9 & 4.2 \\
$\mathrm{CoO}_{x} /$ MZI & 1.7 & 1.7 \\
$\mathrm{CoO}_{x} /$ CZI & 2.3 & 7.6
\end{tabular}

Co. The Co concentrations on the whole particle and the surface of the particle were measured by the analysis of XPS and ICP (induced coupled plasma spectrometer). Table 1 summarizes the analysis results for different samples. The Co concentration on the surface phase (4.2 wt \%) was much higher than that (1.9 wt $\%)$ in the bulk for $\mathrm{CoO}_{x} / \mathrm{MZIW}$. This result indicated that most of the cobalt oxides were dispersed on the surface of MZ. For $\mathrm{CoO}_{x} / \mathrm{MZI}$, the surface Co concentration (1.7 wt \%) was equal to that $(1.7 \mathrm{wt} \%)$ in bulk. Conversely, most of the $\mathrm{CoO}_{x}$ was loaded on the surface of $\mathrm{CZ}$ by impregnation and calcination; the surface Co concentration (7.6 wt \%) was much higher than that in the bulk (2.3 wt \%). This was attributed to nonporosity, a smaller surface area and insufficient surface hydroxyls of CZ. The rich surface hydroxyl groups of the support played an important role in the loading and dispersion of $\mathrm{CoO}_{x}$ by the preparation method of impregnation, drying, water washing, and calcination. It was found that little cobalt was loaded on the surface of $\mathrm{CZ}$, and the dosages of Co were almost completely washed out with water. These phenomena did not occur when MZ acted as the support. These results suggested that $\mathrm{CoO}_{x}$ was anchored on the surface of $\mathrm{MZ}$ by the interaction of $\left[\mathrm{Co}\left(\mathrm{H}_{2} \mathrm{O}\right)_{6}\right]^{2+}$ with the surface hydroxyls of the support. In the preparation method, the Co concentrations on the whole particle increased with increasing of the dosage of $\mathrm{Co}$ and reached to the maximum value around $2 \%$ at the dosage of Co $5 \%$; then the Co concentration did not change with increasing Co dosage, even at dosages of $10 \%$ and 20\%. During impregnation and subsequent drying in air, the complex reacted with both the acidic and basic hydroxyls of MZ to form the $\left(\mathrm{H}_{2} \mathrm{O}\right)_{x} \mathrm{Co}^{2+13+}-\mathrm{O}-\mathrm{Zr}$ link. The excess cobalt, which was not connected directly to the surface of MZ, was almost completely washed out with water in the washing step. Thus, monolayerdispersed $\mathrm{CoO}_{x}$ was formed by calcination. In the preparation method of impregnation, drying, and calcination, the Co concentrations on the whole particle always increased with increasing dosages of Co. Therefore, the multilayer $\mathrm{CoO}_{x}$ was supported on the surface of MZ. To confirm the metallic state of the cobalt incorporated in these samples, these samples were characterized by XPS and UV-vis DRS. The cobalt $2 p$ binding energies were similar for the $\mathrm{CoO}_{x} / \mathrm{MZIW}$ and $\mathrm{CoO}_{x} / \mathrm{MZI}$ samples (Figure 5). The binding energies of 780.4 and 795.5 $\mathrm{eV}$ were for $2 \mathrm{p}_{3 / 2}$ and $2 \mathrm{p}_{1 / 2}$ transitions, respectively. Unfortu- 


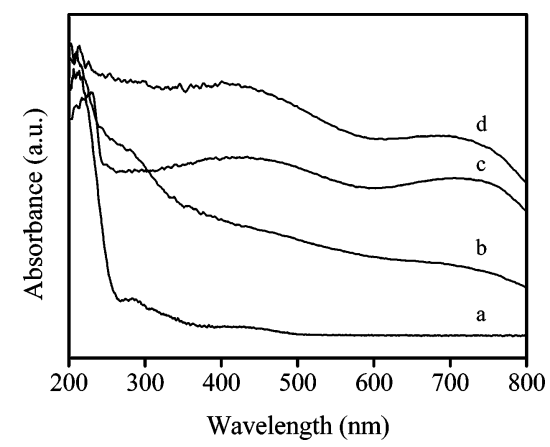

Figure 6. UV-vis diffuse reflectance spectra of different samples: (a) MZ, (b) $\mathrm{CoO}_{x} / \mathrm{MZIW}$, (c) $\mathrm{CoO}_{x} / \mathrm{MZI}$, (d) $\mathrm{CoO}_{x} / \mathrm{CZI}$.

nately, the absolute binding energy of the $2 \mathrm{p}_{3 / 2}$ peak is not always very helpful in identifying the cobalt chemical environment because of the small variation of the binding energy from $\mathrm{Co}^{2+}$ to $\mathrm{Co}^{3+} \cdot{ }^{25,26}$ However, the $2 \mathrm{p}_{3 / 2}$ to $2 \mathrm{p}_{1 / 2}$ separation and satellite structure have elements that are useful in characterizing the cobalt chemical environment. Octahedral $\mathrm{Co}^{2+}$ cations, as found in $\mathrm{CoO}$ for example, have a very intense, characteristic satellite at $\sim 787 \mathrm{eV}$; the approximate position is marked as " $\mathrm{S}$ " in Figure 5. Moreover, the fwhm (full width at half-maximum) of the $2 p_{3 / 2}$ main peak is $3.4 \mathrm{eV}$, which is consistent with the reference data for $\mathrm{Co}_{3} \mathrm{O}_{4} \cdot{ }^{27,28}$ Therefore, there were two types of cobalt (octahedral $\mathrm{Co}^{2+}$ and tetrahedral $\mathrm{Co}^{3+}$ ) contributing to this spectral region. Because UV-vis DRS can provide information regarding the oxidation state of cobalt and its chemical environment, the UV-vis spectra of different samples are shown in Figure 6. The pure MZ spectrum only shows a strong absorption edge with a maximum at about $210 \mathrm{~nm}$ (curve a), which is attributed to charge-transfer transitions from the $2 \mathrm{p}$ level of $\mathrm{O}$ to the $4 \mathrm{~d}$ level of eightfold or sevenfold coordinated $\mathrm{Zr}^{4+} .{ }^{29}$ Both $\mathrm{CoO}_{x} / \mathrm{MZI}$ and $\mathrm{CoO}_{x} / \mathrm{CZI}$ exhibited similar UV-vis spectra (curves c and d). Two broad bands at about 425 and $730 \mathrm{~nm}$ were observed, which indicated the presence of octahedral Co. According to the literature, ${ }^{30}$ the spectra of $\mathrm{CoO}_{x} / \mathrm{MZI}$ and $\mathrm{CoO}_{x} / \mathrm{CZI}$ are almost identical to the spectra for the bulk $\mathrm{Co}_{3} \mathrm{O}_{4} \cdot \mathrm{CoO}_{x} / \mathrm{MZIW}$ exhibited absorption bands in the region of $250-450 \mathrm{~nm}$ (curve b), typically assigned to charge-transfer bands, ${ }^{31}$ reflecting the interaction of $\mathrm{Co}(\mathrm{II})$ ions with mesoporous $\mathrm{ZrO}_{2}$. The results agreed with that of XRD, indicating the strong interaction between $\mathrm{CoO}_{x}$ and $\mathrm{MZ}$ in the sample. Also, $\mathrm{CoO}_{x} / \mathrm{MZIW}$ yielded two weak absorption bands at 425 and $750 \mathrm{~nm}$, indicating that $\mathrm{Co}_{3} \mathrm{O}_{4}$ formed in a very small amount. Comparing the three UV-vis spectra, $\mathrm{CoO}_{x}$ was more highly dispersed on the surface of $\mathrm{MZ}$ for $\mathrm{CoO}_{x} /$ MZIW.

TPR Measurements. The $\mathrm{H}_{2}$-TPR profiles of different catalysts are shown in Figure 7. According to literature, ${ }^{32}$ unsupported $\mathrm{Co}_{3} \mathrm{O}_{4}$ contains one or two peaks close to each other in the temperature range of $200-400{ }^{\circ} \mathrm{C}$. The reduction process is assumed to occur in two steps. One at lower temperature is attributed to the reduction of $\mathrm{Co}^{3+}$ to $\mathrm{Co}^{2+}$, while the other one at slightly higher temperature is assigned to the reduction of $\mathrm{Co}^{2+}$ to $\mathrm{Co}^{0}$. In the TPR curves of $\mathrm{CoO}_{x} / \mathrm{CZI}$ (curve a), two peaks were observed, one at $300{ }^{\circ} \mathrm{C}$ corresponding to the reduction of $\mathrm{Co}_{3} \mathrm{O}_{4}$ to $\mathrm{Co}^{0}, 33$ and the other one at $705{ }^{\circ} \mathrm{C}$ assigned to the reduction of the dispersed $\mathrm{Co}^{2+}$ on the surface of $\mathrm{CZ} .{ }^{33}$ For $\mathrm{CoO}_{x} / \mathrm{MZI}$ (curve b), the two reduction peaks at 315 and $370{ }^{\circ} \mathrm{C}$ were observed for $\mathrm{Co}_{3} \mathrm{O}_{4} \cdot{ }^{34,35}$ The peak at $485{ }^{\circ} \mathrm{C}$ was possibly attributed to the good dispersion of $\mathrm{Co}^{3+} .36$ The $\mathrm{CoO}_{x}$ /MZIW showed two reduction peaks (curve c). One centered at about $565{ }^{\circ} \mathrm{C}$ could be assigned to the well-dispersed $\mathrm{Co}^{3+} ;{ }^{36}$ the other one, centered at about $705^{\circ} \mathrm{C}$, suggested that

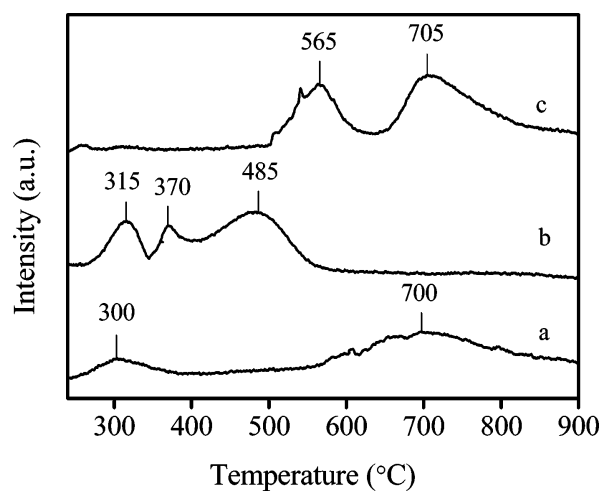

Figure 7. TPR profiles of different samples: (a) $\mathrm{CoO}_{x} / \mathrm{CZI}$, (b) $\mathrm{CoO}_{x} /$ MZI, (c) $\mathrm{CoO}_{x} / \mathrm{MZIW}$.

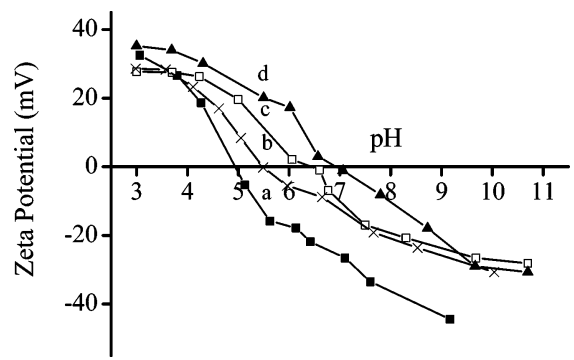

Figure 8. Plot of the zeta potential as a function of $\mathrm{pH}$ for different catalyst suspensions in the presence of $\mathrm{KNO}_{3}\left(10^{-3} \mathrm{M}\right)$. (a) $\mathrm{MZ}$, (b) $\mathrm{CoO}_{x} / \mathrm{MZIW}$, (c) $\mathrm{CoO}_{x} / \mathrm{CZI}$, (d) $\mathrm{CoO}_{x} / \mathrm{MZI}$.

well-dispersed $\mathrm{Co}^{2+}$ was uniformly distributed on the support surface. ${ }^{32}$ The results revealed that Co was highly dispersed on the support for $\mathrm{CoO}_{x} / \mathrm{MZIW}$.

Surface Zeta Potential. The activity of solid catalyst in aqueous solution is relative to its surface charge properties. Figure 8 shows the changes of zeta potential with $\mathrm{pH}$ of the solution. The upward shifts of isoelectric point from the 4.9 value for $\mathrm{MZ}$ used as support were observed after the impregnation of Co. The isoelectric point of $\mathrm{CoO}_{x} / \mathrm{MZIW}, \mathrm{CoO}_{x} / \mathrm{MZI}$, and $\mathrm{CoO}_{x} / \mathrm{CZI}$ were 5.5, 6.4, and 6.9 respectively. Previous studies ${ }^{37}$ showed that the negatively charged surface has a strong reactivity toward ozone. This phenomenon is likely due to the electrophilic characteristics of ozone, which has a high affinity for molecular sites with a strong electronic density. $\mathrm{CoO}_{x} / \mathrm{MZIW}$ possibly had the highest activity.

Ozonation of 2,4-D in the Presence of Supported $\mathrm{CoO}_{x}$. The catalytic activity of different catalysts was evaluated by the degradation of 2,4-D with ozone at $\mathrm{pH} 7$. As shown in Figure 9 , only $28 \%$ of TOC was removed at a reaction time of $40 \mathrm{~min}$ in the presence of ozone alone. However, the TOC removal increased with the addition of different catalysts. About $50 \%$ of TOC was removed at a reaction time of $40 \mathrm{~min}$ in $\mathrm{CoO}_{x} /$ MZI and $\mathrm{CoO}_{x} / \mathrm{CZI}$ suspensions with ozone (curves $\mathrm{c}$ and $\mathrm{d}$ ). The two catalysts exhibited almost the same catalytic ozonation activity. $\mathrm{CoO}_{x} / \mathrm{MZIW}-2$ (from $\mathrm{Co}\left(\mathrm{NO}_{3}\right)_{2}$ ) showed slightly higher activity than them; about $70 \%$ of TOC was removed (curve e). The $\mathrm{CoO}_{x} / \mathrm{MZIW}$ exhibited the highest activity; the TOC content of the 2,4-D solution was greatly reduced, by $90 \%$, in $\mathrm{CoO}_{x} /$ MZIW suspension with ozone (curve f). Forty-three percent of TOC was removed in $\mathrm{Co}^{2+} 1 \mathrm{mg} / \mathrm{L}$ (highest concentration detected in $\mathrm{CoO}_{x} / \mathrm{MZIW}$ during the reaction at $\mathrm{pH}=7$ ) solution with ozone, which is almost the same as that one in the homogeneous catalytic reaction at $\mathrm{pH}=4$ although the released $\mathrm{Co}^{2+}$ concentration is $2 \mathrm{mg} / \mathrm{L}$. The catalytic contribution of homogeneous $\mathrm{Co}^{2+}$ was almost same at different $\mathrm{pH}$. The results indicated that the catalytic activity depended predominantly on 


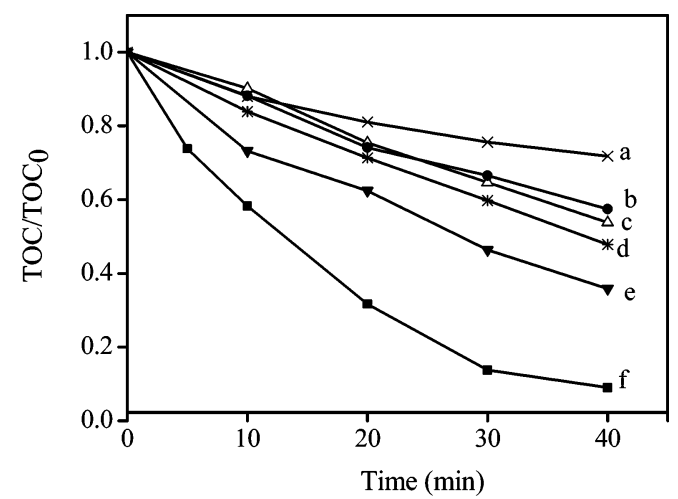

Figure 9. Removal of TOC during the degradation of 2,4-D in aqueous dispersions of various catalysts with ozone: (a) $\mathrm{O}_{3}$, (b) $\mathrm{Co}^{2+} 1 \mathrm{mg} / \mathrm{L}$, (c) $\mathrm{CoO}_{x} / \mathrm{CZI}$, (d) $\mathrm{CoO}_{x} / \mathrm{MZI}$, (e) $\mathrm{CoO}_{x} / \mathrm{MZIW}-2$, (f) $\mathrm{CoO}_{x} / \mathrm{MZIW}$. (pH $=7$, catalyst: $1.5 \mathrm{~g} / \mathrm{L}$, gaseous ozone concentration: $30 \mathrm{mg} / \mathrm{L})$.

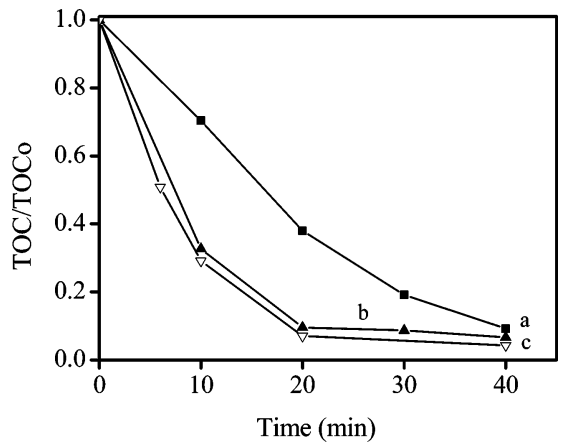

Figure 10. Effect of 2,4-D concentrations on TOC removal in $\mathrm{CoO}_{x} /$ MZIW suspension at $\mathrm{pH}$ 7: (a) $80 \mathrm{mg} / \mathrm{L}$, (b) $20 \mathrm{mg} / \mathrm{L}$, (c) $10 \mathrm{mg} / \mathrm{L}$ (catalyst: $2 \mathrm{~g} / \mathrm{L}$, gaseous ozone: $30 \mathrm{mg} / \mathrm{L}$ ).

the dispersion of Co on the support. The highest dispersion of Co on MZ was obtained by the preparation processes of impregnation, drying, washing with water, and then calcination, leading to the highest activity. The small surface area and insufficient surface hydroxyls of $\mathrm{CZ}$ led to the lower Co dispersion on its surface and the lower activity. The nature of the support, the preparation method, and the Co source played a decisive role in the fabrication of the active phases for Co. The effect of 2,4-D concentrations on the TOC removal was investigated in $\mathrm{CoO}_{x} / \mathrm{MZIW}$ suspension with ozone (Figure 10). The TOC of the reaction solution was almost completely removed within $20 \mathrm{~min}$ at the 2,4-D concentration of $10 \mathrm{mg} / \mathrm{L}$, while about $94 \%$ of TOC was removed within the same reaction time at the 2,4-D concentration of $20 \mathrm{mg} / \mathrm{L}$. Even when the 2,4-D concentration was $80 \mathrm{mg} / \mathrm{L}$, more than $90 \%$ TOC disappeared at $40 \mathrm{~min}$. The results demonstrated that $\mathrm{CoO}_{x} /$ MZIW is a highly efficient catalyst for the mineralization of 2,4-D in the ozonation process. Figure 11 presents the temporal variations of the TOC content of the 2,4-D solution at various concentrations of $\mathrm{CoO}_{x} / \mathrm{MZIW}$. Clearly, the TOC removal rate increased with an increase in the concentration of $\mathrm{CoO}_{x} / \mathrm{MZIW}$, and reached to the maximum at the catalyst concentration of $2 \mathrm{~g} / \mathrm{L}$. The results indicated that there were the maximum active centers for the generation of $\cdot \mathrm{OH}$ at an optimum catalyst concentration. A higher concentration of $\mathrm{CoO}_{x} / \mathrm{MZIW}$ led to the aggregation of the catalyst, causing a decrease in the catalytic activity. The effect of $\mathrm{pH}$ on the TOC removal is shown in Figure 12 . In the tested $\mathrm{pH}$ range, the activity of the catalyst did not change greatly. The removal rate is also similar both at $\mathrm{pH} 7$ and $\mathrm{pH}=10$ with ozone alone. The removal rate of TOC at $\mathrm{pH} 4$ was slightly higher than those at other $\mathrm{pH}$ levels. The isoelectric point of $\mathrm{CoO}_{x} / \mathrm{MZIW}$ was $5.5 \mathrm{pH}$ units. At $\mathrm{pH}<$

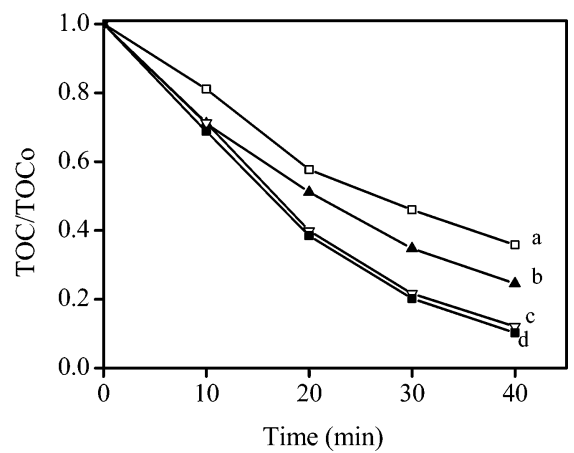

Figure 11. Effect of $\mathrm{CoO}_{x} / \mathrm{MZIW}$ concentrations on TOC removal at pH 7: (a) $1 \mathrm{~g} / \mathrm{L}$, (b) $1.5 \mathrm{~g} / \mathrm{L}$, (c) $2 \mathrm{~g} / \mathrm{L}$, (d) $3 \mathrm{~g} / \mathrm{L}$.

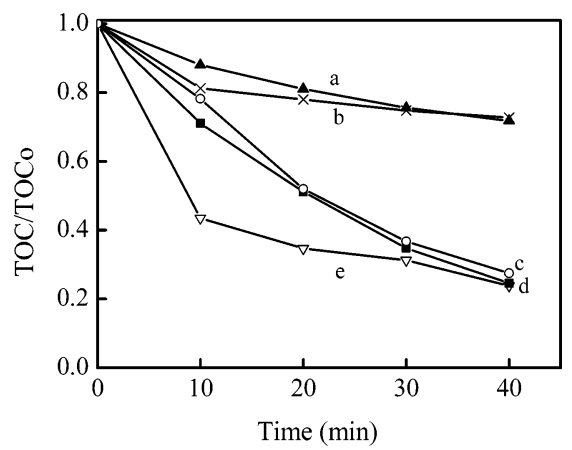

Figure 12. Effect of initial $\mathrm{pH}$ on TOC removal of 2,4-D solution in ozone alone: (a) $\mathrm{pH}=7$, (b) $\mathrm{pH}=10$, and $\mathrm{CoO}_{x}$ /MZIW catalytic ozonation: (c) $\mathrm{pH}=10$, (d) $\mathrm{pH}=7$, (e) $\mathrm{pH}=4$ (catalyst: $1.5 \mathrm{~g} / \mathrm{L}$, gaseous ozone concentration: $30 \mathrm{mg} / \mathrm{L}$ ).

5.5 , the surface of the catalyst was positively charged, while it was negatively charged at $\mathrm{pH}>5.5$. The more $2,4-\mathrm{D}$ adsorbed onto the catalyst at $\mathrm{pH}=4$, the more TOC was removed. Alternatively, ozone reacts readily with the negatively charged surface because of its electrophilic characteristics. A higher efficiency of the catalytic ozonation was still obtained in the range of $\mathrm{pH}$ 7-10 although 2,4-D hardly had any adsorption on the surface of the catalyst under these conditions. This result indicated that more free ${ }^{\circ} \mathrm{OH}$ was generated in the solution by the catalytic transformation of ozone, causing the oxidation of 2,4-D in solution. As shown in Figure S2 (Supporting Information), $\mathrm{CoO}_{x}$ /MZIW did not exhibit any obvious loss of activity when it was further reused for eight cycles. The concentration of $\mathrm{Co}^{2+}$ leached out into solution from $\mathrm{CoO}_{x} / \mathrm{MZIW}$ decreased with increasing cycle times. Moreover, after eight successive cycles, the concentration of Co in the bulk of the catalyst was 1.8 wt $\%$, slightly less than that one 1.9 wt $\%$ in the fresh sample.

Mechanism Discussion. In order to confirm this reaction mechanism, the involved active species were investigated in the catalytic ozonation of 2,4-D. tert-Butanol is a strong radical scavenger that has the reaction rate constant of $6 \times 10^{8} \mathrm{M}^{-1} \mathrm{~s}^{-1}$ with hydroxyl radicals and only $3 \times 10^{-3} \mathrm{M}^{-1} \mathrm{~s}^{-1}$ with ozone. It can terminate radical chain reactions by generating inert intermediates. Thus, tert-butanol was adopted as the indicator for the radical-type reaction. At $\mathrm{pH}=7,2,4-\mathrm{D}$ was hardly adsorbed on the surface of $\mathrm{CoO}_{x} / \mathrm{MZIW}$. The oxidation reaction of 2,4-D occurred mainly in solution. The adsorption ratio of tert-butanol was $5.2 \%$ on the surface of $\mathrm{CoO}_{x} / \mathrm{MZIW}$ at $\mathrm{pH}=$ 7. Therefore, tert-butanol could trap ${ }^{\circ} \mathrm{OH}$ both in solution and on the surface of the catalyst. As shown in Figure S3 (Supporting Information), the addition of tert-butanol markedly reduced the ozonation of 2,4-D at $\mathrm{pH} 7$ in the presence of $\mathrm{CoO}_{x}$ / MZIW. This result indicated that ${ }^{\circ} \mathrm{OH}$ was the main active 
species in the catalytic ozonation reaction. $\mathrm{CoO}_{x} / \mathrm{MZIW}$ accelerated more ozone transformation into ${ }^{\circ} \mathrm{OH}$. Meanwhile, a series of ozone decomposition experiments were carried out in the presence of $\mathrm{CoO}_{x} / \mathrm{MZIW}$. As shown in Figure S4 (Supporting Information), only $50 \% \mathrm{O}_{3}$ was decomposed within $15 \mathrm{~min}$ without catalyst (curve a), while the ozone decomposition rate was markedly enhanced in the presence of different catalysts. $\mathrm{MnO}_{x} / \mathrm{MZIW}$ exhibited the highest activity (curve d); $\mathrm{O}_{3}$ was almost completely decomposed within $5 \mathrm{~min}$. $\mathrm{MnO}_{x} / \mathrm{CZI}$ showed the least activity (curve b). The ozone decomposition occurred in parallel with the TOC removal in different catalyst suspensions. These results indicated that the supported $\mathrm{CoO}_{x}$ could catalytically decompose $\mathrm{O}_{3}$ into ${ }^{\circ} \mathrm{OH}$. According to the previous work, ${ }^{38}$ the mechanism of ozone decomposition on the catalyst consists of mainly redox steps: adsorption of ozone on the catalyst, and desorption of the adsorbed intermediates. Consquently, the faster the catalyst undergoes oxidation and reduction, the faster the rate of the decomposition reaction. The multiple oxidation states of $\mathrm{Co}$ in $\mathrm{MnO}_{x} / \mathrm{MZIW}$ enhanced the electron transfer, resulting in higher activity. According to the mechanism, the surface Co on the support is active component. Thus, the turnover frequency (TOF) of $\mathrm{CoO}_{x} / \mathrm{MZIW}, \mathrm{CoO}_{x} /$ MZI, and $\mathrm{CoO}_{x} / \mathrm{CZI}$ obtained was $0.265,0.176$, and $0.137 \mathrm{~s}^{-1}$, respectively, based on Table 1 . Therefore, the dispersion and oxidation state of the supported $\mathrm{CoO}_{x}$ were crucial factors for the high efficiency of the catalytic ozonation.

\section{Conclusions}

$\mathrm{CoO}_{x}$ was highly dispersed on the surface of $\mathrm{MZ}$ at the monolayer by the impregnation of the cobalt acetate tetrahydrate solution, followed by drying, water washing, and calcination. The supported $\mathrm{CoO}_{x}$ existed mainly as $\mathrm{Co}_{3} \mathrm{O}_{4}$ phase in $\mathrm{CoO}_{x} /$ MZIW, $\mathrm{CoO}_{x} / \mathrm{MZI}$, and $\mathrm{CoO}_{x} / \mathrm{CZI}$. The strong interaction of Co species with $\mathrm{MZ}$ was verified in the structure of $\mathrm{CoO}_{x} /$ MZIW. The surface hydroxyls and water washing played an important role in the high dispersion of Co on the surface of MZ. The $\mathrm{CoO}_{x} / \mathrm{MZIW}$ exhibited the highest activity for the mineralization of 2,4-D with ozone. The multivalence oxidation states and high dispersion of $\mathrm{CoO}_{x}$ in the catalyst enhanced the interfacial electron transfer, leading to high reactivity.

Acknowledgment. This work was supported by the National 863 Project of China (grant no. 2006AA06Z304 and 2006AA06Z307) and the National Natural Science Foundation of China (nos. 50778169 and 50621804).

Supporting Information Available: XRD of $\mathrm{CZ}$ and $\mathrm{CoO}_{x}$ / $\mathrm{CZ}$, recycle experiment, effect of tert-butanol on 2,4-D removal and ozone decomposition. This material is available free of charge via the Internet at http://pubs.acs.org.

\section{References and Notes}

(1) Andreozzi, R.; Insola, A.; Carpio, V.; Marotta, R.; Tufano, V. Appl. Catal., A 1996, 138, 75.

(2) Legube, B.; Leitner, N. K. V. Catal. Today 1999, 53, 61

(3) Lin, S.-S.; Gurol, M. D. Environ. Sci. Technol. 1998, 32, 1417.

(4) Dionysiou, D. D.; Suidan, M. T. Appl. Catal., B 2000, 26, 153.

(5) Gracia, R.; Cortes, S.; Sarasa, J.; Ormad, P.; Ovelleiro, J. L. Water Res. 2000, 34, 1525.

(6) Villaseñor, J.; Reyes, P.; Pecchi, G. Catal. Today 2002, 76, 121.

(7) Cooper, C.; Burch, R. Water Res. 1999, 33, 3695.

(8) Konova, P.; Stoyanova, M.; Naydenov, A.; Christoskova, S.; Mehandjiev, D. Appl. Catal., A 2006, 298, 109.

(9) Castner, D. G.; Watson, Ph. R.; Chan, I. Y. J. Phys. Chem. 1989, 93, 3188.

(10) Jansson, J. J. Catal. 2000, 194, 55.

(11) Pietrogiacomi, D.; Tuti, S.; Campa, M. C.; Indovina, V. Appl. Catal., B 2000, 28, 43 .

(12) Garbowski, E.; Guenin, M.; Marion, M. C.; Primet, M. Appl. Catal., $B$ 1990, 64, 209.

(13) Álvarez, P. M.; Beltránl, F. J.; Pocostales, J. P.; Masa, F. J. Appl. Catal., B 2007, 72, 322.

(14) Huang, W.-J.; Fang, G.-C.; Wang, C.-C. Colloids Surf., A 2005, 260,45 .

(15) Han, Y. F.; Chen, F. X.; Zhong, Z. Y.; Ramesh, K.; Chen, L. W.; Widjaja, E. J. Phys. Chem. B 2006, 110, 24450.

(16) Brillas, E.; Calpe, J. C.; Cabot, P. L. Appl. Catal., B 2003, 46, 381.

(17) Pignatello, J. Environ. Sci. Technol. 1992, 26, 944.

(18) Zepp, R. G.; Faust, B. C.; Hoigne, J. Environ. Sci. Technol. 1992, 26,313 .

(19) Trillas, M.; Peral, J.; Domenech, X. Appl. Catal., B 1995, 5, 377.

(20) Liu, X. L., G.; Yan, Z. J. Phys. Chem. B 2004, 108, 11523.

(21) Blin, J.; Flamant, R.; Su, B. Int. J. Inorg. Mater. 2001, 3, 959.

(22) Kasprzyk-Hordern, B.; Ziółek, M.; Nawrocki, J. Appl. Catal., B 2003, 46, 639 .

(23) Okamoto, Y.; Kubota, T.; Ohto, Y.; Nasu, S. J. Phys. Chem. B 2000, 104, 8462 .

(24) Dong, Q.; Zhou, X.; Shao, S. Ion Exch. Adsorp. 2006, 22, 363.

(25) Jimenez, V. M.; Fernandez, A.; Espinos, J. P.; Gonzales-Elipe, A. R. J. Electron Spectrosc. Relat. Phenom 1995, 71, 61.

(26) Brundle, C. R.; Chuang, T. J.; Rice, D. W. Surf. Sci. 1976, 60 , 286.

(27) Kim, J. G.; Pugmire, D. L.; Battaglia, D.; Langell, M. A. Appl. Surf. Sci. 2000, 165, 70 .

(28) Tang, Q. H.; Zhang, Q. H.; Wang, P.; Wang, Y.; Wan, H. L. Chem. Mater. 2004, 16, 1967.

(29) López, E. F.; Escribano, V. S.; Gallardo-Amores, J. M.; Resini, C.; Busca, G. Solid State Sci. 2002, 4, 951.

(30) Liotta, L. F.; Pantaleo, G.; Macaluso, A.; Di Carlo, G.; Deganello, G. Appl. Catal., A 2003, 245, 167.

(31) Vinu, A.; Ddeek, J.; Murugesan, V.; Hartmann, M. Chem. Mater. 2002, 14, 2433

(32) Vakros, J.; Kordulis, C.; Lycourghiotis, A. Langmuir 2002, 18, 417.

(33) Infantes-Molina, A.; Merida-Robles, J.; Rodriguez-Castellon, E.; Fierro, J. L. G.; Jimenez-Lopez, A. J. Catal. 2006, 240, 258.

(34) Sun, S.; Tsubaki, N.; Fujimoto, K. Appl. Catal., A 2000, 202, 121.

(35) Boot, L. A.; Kerkhoffs, M. H. J. V.; van Dillen, A. J.; Geus, J. W.; van Buren, F. R.; van der Linden, B. T. Appl. Catal., A 1996, 137, 69.

(36) Arnoldy, P.; Moulijn, J. A. J. Catal. 1985, 93, 38.

(37) Park, J. S.; Choi, H.; Cho, J. Water Res. 2004, 38, 2285. 9041. 